\title{
The Use of Online Quizzes for Continuous Assessment and Self- Assessment of Second-Language Learners
}

\author{
Ana $\mathrm{M}^{\mathrm{a}}$ Pinto-Llorente \\ Faculty of Education, Pontifical \\ University of Salamanca \\ Henry Collet Street, 52-70, \\ Salamanca 37007, Spain \\ (+34) 923125027 \\ ampintoll@upsa.es \\ Ma Cruz Sánchez-Gómez
}

\author{
Faculty of Education, University \\ of Salamanca \\ Promenade Canalejas, 169, 37008, \\ Salamanca, Spain \\ (+34) 923294630, ext. 3404 \\ mcsago@usal.es \\ Francisco José García- \\ Peñalvo \\ Sonia Casillas Martín
}

Faculty of Education, University of Salamanca

Promenade Canalejas, 169, 37008, Salamanca, Spain

(+34) 923294630 , ext. 3403

scasillasma@usal.es
Faculty of Sciences, University of

Salamanca

Caídos Square s/n, 37008,

Salamanca, Spain

(+34) 923294500 , ext. 1302

fgarcia@usal.es

\begin{abstract}
The present study involved a quantitative research with an ex-post facto design. We aimed to explore participants' perceptions about the effectiveness of using online assessment and self-assessment quizzes to improve their level of English, to provide them a significant and effective feedback, to support autonomous learning, and to give them the opportunity to direct their learning. The study was based on a sample of 358 students who were recruited from the Faculty of Education at the Pontifical University of Salamanca, and were all enrolled in the subject English I. Participants ranged in age from 20 to 58 with an average age of 29.49 and were divided into four age groups (2024, 25-29, 3034 and 35 or more than 35). The descriptive and inferential analysis provided evidences about the positive students' perception of the effectiveness of online assessment and self-assessment quizzes towards the possibilities they offered to practice and improve their level of English, to motivate their learning, and to encourage the study of the subject. The results also suggested the relevance of online quizzes to support autonomous learning, and the potential of immediate feedback to guide participants' learning.
\end{abstract}

\section{CCS Concepts}

- Applied computing $\rightarrow$ Education $\rightarrow$ Learning management systems

\section{Keywords}

Continuous assessment; self-assessment; online quizzes; English as L2; autonomous learning

\section{INTRODUCTION}

This study reports on the main results of a research concerning the students' perception about the effectiveness of online quizzes to carry out the continuous assessment and self-assessment, as well as to favor the students' autonomous learning and their level of English.

Second language learners are progressively expected to be responsible for their own learning and achievements, and to know their needs through the process of self-assessment. For the purpose of our research, we followed the definition of self-assessment developed by Andrade and $\mathrm{Du}$ [1] who consider it as "a process of formative assessment during which students reflect on and evaluate the quality of their work and their learning, judge the degree to which they reflect explicitly stated goals or criteria, identify strengths and weaknesses in their work, and revise accordingly". In that definition they emphasize learners' responsibility of their learning, their active engagement in their progress and the reflection on the goals to achieve.

On one hand, continuous assessment (CA) is considered one of the most relevant characteristics of the assessment system of the European Higher Education Area (EHEA). It can be defined as an assessment approach in which students' final grading takes over a period of time in which teachers gather, interpret and synthesize learners' results in order to monitor instruction [2, 14]. As Moges [14] states continuous assessment must be planned, be suited to students' age and level, and must provide students a formative feedback to guide their learning, and help them to achieve the goals.

On the other hand, the possibilities provided by the development of ICT allow teachers to design the necessary activities to carry out both self-assessment and continuous assessment in Blended-learning training. As Steegmann et al. [20] point out the Learning Management system Moodle and its tools have provided the possibilities to develop quality online courses. In our research we have concentrated on the potential of online quizzes and their effectiveness to perform continuous assessment and self-assessment. 
In the following parts of our paper, we provide an overview of the study. First of all, we introduce the research by providing the quantitative research method used, an ex-post-facto design because we only recorded the measures without manipulating the variables, since the phenomenon occurred naturally. The present study was based on a sample of 358 students who were recruited from a population of 451 and were enrolled in the subject English I, developed under blended learning modality. To operationalize the variables and collect the data of our research, we used a pre-test and post-test which were available in the virtual campus of that subject during one week at the beginning and at the end of the course. Secondly, we present the main quantitative results of the descriptive and inferential analysis conducted. For the purposes of the present research, we focused our analysis on the obtained data on the following five sections: 3.1 . written skills, grammar contents and vocabulary; 3.2. feedback provided by the quizzes, 3.3. efficacy of the quizzes, 3.4. quizzes as tools to support autonomous learning, and 3.5. students and teachers' roles. Finally, we show the main conclusions of our research according to our students' perceptions and attitudes towards the effectiveness of online assessment and self-assessment quizzes towards the possibilities they offered to practice and improve their level of English, to motivate their learning, and to encourage the study of the subject.

\section{METHOD}

The present research involved a quantitative research $[8,9,12]$ with an ex-post facto design. We only recorded the measures without manipulating the variables, since the phenomenon occurred naturally. Cohen et al. [7] stated that "when we translate literally, ex-post-facto means 'from what is done afterwards.' In the context of social and educational research, the phase means 'after the fact' or 'retrospectively' and refers to those studies which investigate possible cause-and-effect relationships by observing an existing condition or state of affairs and searching back in time for plausible causal factors."

Bearing in mind the classification of non-experimental research developed by Arnal, Rincón, and Latorre [4], our study addressed a descriptive study, a survey method, using techniques of descriptive and inferential analysis for the different strata sample of the research.

\subsection{Objectives and Hypotheses}

This quantitative study aimed to explore the students' perceptions about the effectiveness of using online assessment and self-assessment quizzes:

- to improve their level of English: written skills, grammar contents and vocabulary;

- to provide them a significant and effective feedback;

- to support autonomous learning; and

- to give them the opportunity to direct their learning.

Our study focused on the next hypotheses:

H1. The participants will improve their level of English in terms of written skills, grammar contents, and vocabulary through the use of assessment and self-assessment quizzes.

H2. The feedback provided is effective to guide their learning and provided them a more realistic impression of their level of the second language.

H3. The self-assessment quizzes will support autonomous learning.

H4. The self-assessment quizzes will help students to be aware of their necessities in their second language, and to take responsibility for their learning.

\subsection{Population and Sample}

The participants were 358 students from the third year of the Degree in Primary Education: English. They attended to the Faculty of Education at the Pontifical University of Salamanca, and were all enrolled in the subject English I whose objectives were to develop the students' communicative competence and master the linguistic code of English which allows them to use this language in an accurate way. The grammatical contents in this subject were: I. Correct use of articles, pronouns, adjectives, adverbs, prepositions, verbs: (auxiliaries, modals, verb tenses, phrasal verbs) and connectors. II. Sentence patterns: infinitive/-ing, passive voice, adverbial clauses, relative clauses and reported speech. III. Use of language: collocations, word-formation, rephrasing, cloze and multiple-choice activities, and error correction. 
Participants ranged in age from 20 to 58 with an average age of $29.49(\mathrm{SD}=5.99), 23.2 \%$ were men $(\mathrm{n}=83)$ and $76.8 \%$ women $(\mathrm{n}=275)$. Most of them were working (70.7\%) in different levels of education: infant (22.1\%), primary (28.2\%) and secondary education (7.3\%).

In regard to the reasons to study the Degree in Primary Education: English, more than half of the participants $(51,40 \%$, n=184) stated that they would have more professional opportunities, and $23.2 \%(n=83)$ pointed out that they would have more professional opportunities and would improve their communicative competence in English.

\subsection{Variables and Instrument}

We used two tests to operationalize the variables and collect the data of our research. These instruments were reviewed by different researchers specialized in English as a second language, technology, and education research. The participation of these experts provided the external validity.

On the other hand, we calculated Cronbach's alpha in order to estimate the internal consistency or average correlation of the items in the pre-test and post-test, and to gauge their reliability. The internal consistency of the pre-test was $\alpha=0.832$, and in the post-test $\alpha=0.867$. We stated that the items of both tests had high internal consistency, taking into account their alpha coefficient.

\subsubsection{Socio-Demographics Characteristics}

At the beginning of the questionnaires we included items about gender, age, and the reasons to study the Degree in Primary Education: English.

\subsubsection{Written Skills, Grammar Contents, and Vocabulary}

Our questionnaires contained 4 items that provided measures about the students' perception about the adequacy of the quizzes to practice their written skills as well as grammar contents and vocabulary. We used a five point Likert scale to code their answers: $1=$ 'poor', $2=$ 'fair', 3 = 'good', 4 = 'very good' and 5 = 'excellent'.

\subsubsection{Feedback Provided by the Quizzes}

In that part of the post-test students were asked to evaluate the feedback provided. The participants assessed the immediacy of it using a Likert scale where 1 = 'totally disagree', 20 'disagree', 3 = 'neither agree nor disagree', 4 = 'agree' and $5=$ 'totally agree'. The same scale were used for the items that referred to the adequacy of the feedback to guide participants' learning, and to provide them a more realistic impression of their level of reading, listening, grammar competence and vocabulary

\subsubsection{Efficacy of the Quizzes}

That part of the post-test contained 12 items. Participants were asked about the efficacy of the quizzes to get the learning objectives, to motivate their learning, to encourage the study of the subject, to help them to determine language proficiency, to reflect about the second language, to work more continuously and systematically, to self-monitor their learning towards specific objectives of the subject, to allow them to take responsibility for their learning and decide what and when to learn, to help them to be in contact with the subject, to feel more motivated and interested in the subject, to know their progress in the subject, and to feel more confident to take the assessment ones. In that case, we used a five-point Likert scale to code their answers: $1=$ 'Absolutely ineffective', 2 = 'Very ineffective', $3=$ 'Neither effective nor ineffective', 4 = 'Very effective' and $5=$ 'Absolutely effective'.

\subsubsection{Quizzes as Tools to Support Autonomous Learning}

Participants were also asked about the efficacy of the online quizzes to support autonomous learning. We coded their answers using the five-point Likert scale mentioned previoasly where 1/= 'Absolutely ineffective', 2 = 'Very ineffective', 3 = 'Neither effective nor ineffective', 4 = 'Very effective' and $5=$ 'Absolutely effective'.

\subsubsection{Students and Teachers' Roles}

In the last part of the post-test they had to answer the questions that referred to the idea of the students acting as assessors, and the teachers as guides and counselors. We used a five-point Likert scale to code their answer. The values assigned to that scale were: $1=$ 'totally disagree', 20 'disagree', 3 = 'neither agree nor disagree', 4 = 'agree' and 5 = 'totally agree'.

\subsection{Data Collection and Analysis}

To collect the data of the study, two surveys were available in the virtual campus of the subject English I during one week at the beginning and at the end of the course. After collecting the data, we coded and entered them in the SPSS 24 database. We carried out a descriptive (frequencies), and inferential (paired sample t-tests, and analysis of variance) analysis.

\section{RESULTS}

In the following subsections we present the main results of the descriptive and inferential analysis conducted: 3.1 . written skills, grammar contents and vocabulary; 3.2. feedback provided by the quizzes, 3.3. efficacy of the quizzes, 3.4. quizzes as tools to support autonomous learning, and 3.5. students and teachers' roles.

\subsection{Written Skills, Grammar Contents and Vocabulary}

The analysis of the data that referred to the adequacy of the quizzes to practice reading comprehension led to results that showed that $56.3 \%(n=202)$ of the participants considered that they were very good, $20.9 \%(n=75)$ good, and $18.7 \%(67)$ excellent. Similar results were obtained in the analysis of the dependent variables that referred to the adequacy of quizzes to practice listening comprehension (good: 
$24.2 \% n=87$, very good: $54 \% n=194$, and excellent: $13.4 \% n=48$ ), to practice grammar contents (good: $18.1 \% n=65$, very good: $59.3 \%$ $n=213$, and excellent: $18.7 \% n=67$ ), and to acquire vocabulary (good: $19.2 \% n=69$, very good: $58.2 \% n=209$, and excellent: $18.7 \% n=67$ ).

The participants self-assessed their level of reading, listening, grammatical competence, and vocabulary at the beginning and at the end of the course, the results obtained in the pair samples test revealed that there were statistically significant differences (CI 95\%) between all these items (Table 1). We rejected the null hypothesis, and affirmed that there was a relationship between the students' perception about the efficacy of the online Moodle quizzes, and their improvement of all these aspects of the second language (H1).

Table 1. Paired Samples Correlations

\begin{tabular}{|c|c|c|c|c|}
\hline & & $\mathrm{t}$ & Correlation & Sig. \\
\hline Pair 1 & Reading \& Reading & -14.525 & .133 & .012 \\
\hline Pair 2 & $\begin{array}{l}\text { Listening \& } \\
\text { Listening }\end{array}$ & -23.555 & .112 & .033 \\
\hline Pair 3 & $\begin{array}{l}\text { Grammatical } \\
\text { Competence \& } \\
\text { Grammatical } \\
\text { Competence }\end{array}$ & -20.643 & .121 & .022 \\
\hline Pair 4 & $\begin{array}{l}\text { Vocabulary \& } \\
\text { Vocabulary }\end{array}$ & -33.868 & .110 & .037 \\
\hline
\end{tabular}

\subsection{Feedback Provided by the Quizzes}

The participants of the study were asked if they agreed or not with the idea that the quizzes provided them an immediate feedback, the results pointed out that $52.9 \%(\mathrm{n}=190)$ agreed and $29.0 \%(\mathrm{n}=104)$ totally agreed with that statement. Similar results were obtained in the dependent variable that referred to the adequacy of feedback to guide their learning. In that case $51.5 \%(n=185)$ agreed and $25.6 \%(n=92)$ totally agreed.

Regarding their perception about the possibilities that this feedback provided them to have a more realistic impression of their level of reading, listening, grammar competence and vocabulary, the results confirmed that most students answered that they agreed $(58.8 \% \mathrm{n}=211$, $55.7 \% \mathrm{n}=200,60.2 \% \mathrm{n}=216$ and $58.5 \% \mathrm{n}=210)$ or totally agreed $(29 \% \mathrm{n}=104,27.9 \mathrm{n}=100,28.7 \% \mathrm{n}=103$ and $27.3 \% \mathrm{n}=98)$ with these statements.

\subsection{Efficacy of the Quizzes}

With regard to the dependent variables that referred to the efficacy of the quizzes to get learning objectives, to motivate their learning, and to encourage the study of the subject (item 2), the majority of the participants considered that they were very effective $(48.2 \%$, $n=173$; $44.3 \%, n=159$ and $45.4 \%, n=163$, respectively) or absolutely effective $(27.6 \%, n=99 ; 29.8 \%, n=107$ and $29.8 \%$, $n=107$, respectively). The analysis of the data of these dependent variables also revealed that there were statistically significant differences (CI 95\%) between age groups $(\mathrm{p}=.000, \mathrm{p}=.000$ and $\mathrm{p}=.000)$. We calculated the Scheffe post-hoc test (Table 2$)$ that showed there were statistically significant differences between the mean of the youngest $(20-24: \bar{x}=4.56, \bar{x}=4.60, \bar{x}=4.56$; and 25-29: $\bar{x}=4.48, \bar{x}=4.52, \bar{x}=4.53)$ and the oldest participants of the study ( 30 and $34: \bar{x}=3.55, \bar{x}=3.51, \bar{x}=3.56$; and between 35 or more than $35: \bar{x}=3.44, \bar{x}=3.40, \bar{x}=3.40$ ).

\begin{tabular}{|c|c|c|c|c|}
\hline \multicolumn{5}{|c|}{ Table 2. Multiple Comparisons } \\
\hline & $\begin{array}{l}\text { (I) Group } \\
\text { of Age }\end{array}$ & $\begin{array}{l}\text { (J) Group of } \\
\text { Age }\end{array}$ & $\begin{array}{c}\text { Mean } \\
\text { Difference } \\
(\mathrm{I}-\mathrm{J})\end{array}$ & Sig. \\
\hline \multicolumn{5}{|c|}{$\begin{array}{l}\text { Dependent variable: Efficacy of Quizzes to Get the } \\
\text { Learning Objectives }\end{array}$} \\
\hline \multirow[t]{4}{*}{ Scheffe } & \multirow[t]{2}{*}{$20-24$} & $30-34$ & $1.015^{*}$ & .000 \\
\hline & & $\begin{array}{l}35 \text { or more } \\
\text { than } 35\end{array}$ & $1.127^{*}$ & .000 \\
\hline & \multirow[t]{2}{*}{$25-29$} & $30-34$ & $.930 *$ & .000 \\
\hline & & $\begin{array}{l}35 \text { or more } \\
\text { than } 35\end{array}$ & $1.042 *$ & .000 \\
\hline \multicolumn{5}{|c|}{$\begin{array}{l}\text { Dependent variable: Efficacy of Quizzes to Motivate their } \\
\text { Learning }\end{array}$} \\
\hline \multirow[t]{4}{*}{ Scheffe } & \multirow[t]{2}{*}{$20-24$} & $30-34$ & $1.090^{*}$ & .000 \\
\hline & & $\begin{array}{l}35 \text { or more } \\
\text { than } 35\end{array}$ & $1.198 *$ & .000 \\
\hline & \multirow[t]{2}{*}{$25-29$} & $30-34$ & $1.014^{*}$ & .000 \\
\hline & & $\begin{array}{l}35 \text { or more } \\
\text { than } 35\end{array}$ & $1.122^{*}$ & .000 \\
\hline \multicolumn{5}{|c|}{$\begin{array}{l}\text { Dependent variable: Efficacy of Quizzes to Encourage the } \\
\text { Study of the Subject }\end{array}$} \\
\hline Scheffe & $20-24$ & $30-34$ & $.999 *$ & .000 \\
\hline
\end{tabular}




\begin{tabular}{llccc} 
& $\begin{array}{l}35 \text { or more } \\
\text { than } 35\end{array}$ & $1.163 *$ & .000 \\
\hline $25-29$ & $30-34$ & $.968^{*}$ & .000 \\
\hline & $\begin{array}{l}35 \text { or more } \\
\text { than 35 }\end{array}$ & $1.133^{*}$ & .000 \\
\hline *. The mean difference is significant at the .05 level. $\mathrm{n}=358$
\end{tabular}

Concerning the dependent variables that refer to the efficacy of the quizzes to help them to determine language proficiency, to reflect about the second language, to work more continuously and systematically, and to self-monitor their learning towards specific objectives of the subject, the majority of the students assessed them as very effective $(51.5 \% \mathrm{n}=185,44.6 \% \mathrm{n}=160,44.3 \% \mathrm{n}=159$, and $44.6 \% \mathrm{n}=160$, respectively) and absolutely effective $(30.4 \% \mathrm{n}=109,33.7 \% \mathrm{n}=121,30.4 \% \mathrm{n}=109$, and $28.7 \% \mathrm{n}=103$, respectively).

From the data, we stated that there were statistically significant differences (CI 95\%) in the mean of the age groups in the dependent variable that referred to the quizzes as effective tools to determine language proficiency $(\mathrm{p}=.000)$, to work more continuously and systematically $(p=.000)$ and to self-monitor their learning towards specific objectives of the subject ( $p=.000)$. We calculated the Scheffe post-hoc test (Table 3 ) that showed there were statistically significant differences between the mean of the youngest $(20-24: \bar{x}=4.40$ and $\bar{x}=4.16)$ and the participants of the groups of students aged between $30-34$, and between 35 or more than $35(30-34: \bar{x}=3.99$ and $\bar{x}=3.81$, and 35 or more than $35: \bar{x}=3.71$ and $\bar{x}=3.62)$. And also between the mean of the group of students aged between $25-29(\bar{x}=4.17$ and $\bar{x}=4.12$ ) and the oldest ones (35 or more than $35: \bar{x}=3.71$ and $\bar{x}=3.62$ ) in the dependent variable of the effectiveness of quizzes to determine language proficiency and to self-monitor their learning towards specific objectives of the subject. Regarding the dependent variable that referred to the effectiveness of quizzes to work more continuously and systematically, the Scheffe post-hoc test (Table 3 ) also revealed that there were statistically significant differences between the mean of the youngest $(20-24: \bar{x}=4.45)$ and the rest of the participants of the study $(25-29: \bar{x}=4.09,30-34: \bar{x}=3.72,35$ or more than $35: \bar{x}=3.82)$.

\section{Table 3. Multiple Comparisons}

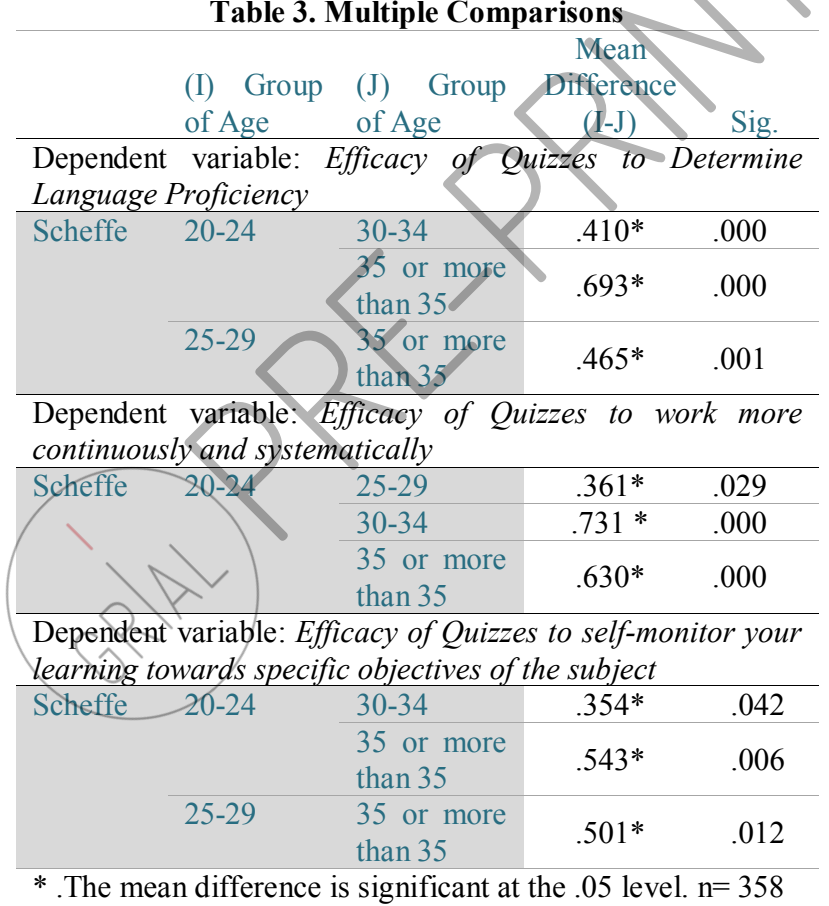

Our findings also indicated that $47.4 \%(n=170)$ considered that the quizzes were very effective, and $31.5 \%(n=113)$ absolutely effective to allow them to take responsibility for their own learning and decide what and when to learn. When asked if the self-assessment quizzes were effective to know their progress in the subject, to help them to be in contact with the subject, to feel more motivated and interested in the subject, and to feel more confident to take the assessment quizzes, 37\% $(\mathrm{n}=133), 43.7 \%(\mathrm{n}=156), 53.5 \%(\mathrm{n}=192)$, and $44.8 \%(\mathrm{n}=161)$ of the participants, respectively, reported that they were very effective, and $35.7 \%(n=128), 31.6 \%(n=113), 28.4 \%(n=102)$, and $29 \%(n=104)$, respectively, absolutely effective.

From the results, so far, we stated that there were statistically significant differences (CI 95\%) in the mean of the age groups in the dependent variable that referred to the quizzes as effective tools to self-direct their learning $(\mathrm{p}=.003)$, to know their progress in the subject $(\mathrm{p}=.002)$, to feel more confident to take the assessment ones $(\mathrm{p}=.000)$, and to feel more motivated and interested in the subject $(\mathrm{p}=.000)$. The Scheffe post-hoc test (Table 4) indicated that there were statistically significant differences between the youngest participants (20-24: $\bar{x}=4.30$ ) and the oldest students of the study ( 35 or more $\tan 35: \bar{x}=3.82$ ) in the dependent variable that referred to the effectiveness of 
quizzes to direct their learning. These differences also happened in the variable that referred to the effectiveness of quizzes to know their progress in the subject between the youngest $(20-24: \bar{x}=4.32)$ and the oldest $(30-34: \bar{x}=3.95$, and 35 or more than $35: \bar{x}=3.78)$.

Finally, the Scheffe post-hoc test (Table 4) revealed that there were statistically significant differences in the variables that referred to the effectiveness of quizzes to feel more confident to take the assessment ones, and to feel more motivated and interested in the subject. The differences here were between the youngest $(20-24: \bar{x}=4.37 \& \bar{x}=4.31$, and 25-29: $\bar{x}=4.35 \& \bar{x}=4.32)$ and the oldest students (30-34: $\bar{x}=3.71 \& \bar{x}=4.00$, and 35 or more than $35: \bar{x}=3.35 \& \bar{x}=3.44)$, and also between the mean of the group of students aged between $30-34$ $(\bar{x}=3.71$ and $\bar{x}=4.00)$ and the oldest ones ( 35 or more than $35: \bar{x}=3.35$ and $\bar{x}=3.44)$

Table 4. Multiple Comparisons

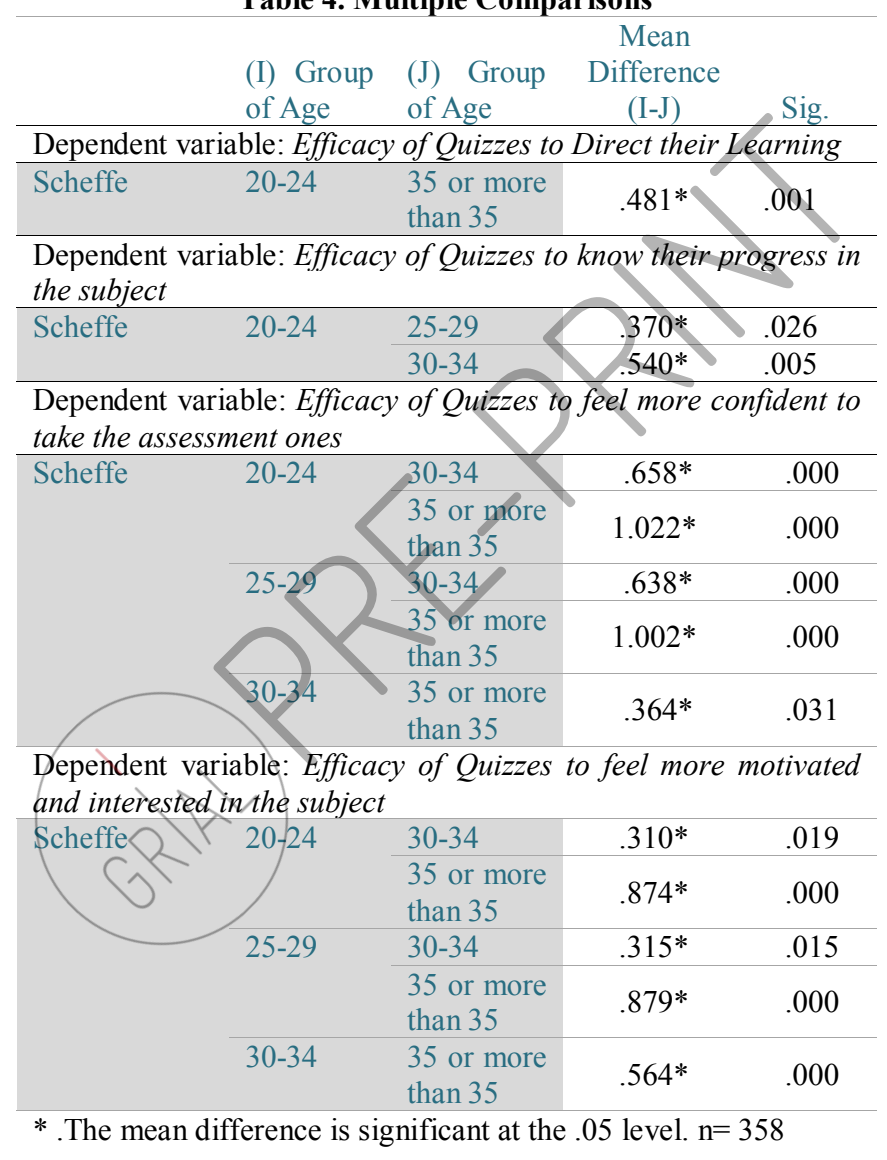

\subsection{Quizzes as Tools to Support Autonomous Learning}

Positive opinions of the quizzes as tools to support autonomous learning were also evident in the results obtained in which 159 of the 358 participants $(44.3 \%)$ considered that they were very effective, and 109 of the 358 participants $(30.4 \%)$ reacted very favorably and assessed them as absolutely effective. These findings clearly demonstrate that the quizzes granted the participants to take an active role of their progress in the second language and to stay focused on the subject. The analysis of the data also indicated that there were statistically significant differences (CI 95\%) between age groups $(\mathrm{p}=.004)$. The Scheffe post-hoc test (Table 5) showed there were statistically significant differences between the mean of the youngest $(20-24: \bar{x}=4.18)$ and the oldest participants of the study (35 or more than 35 : $\bar{x}=3.69)$.

Table 5. Multiple Comparisons

(I) Group (J) Group Mean




\begin{tabular}{lcccc}
\hline \multicolumn{1}{c}{ of Age } & of Age & $\begin{array}{c}\text { Difference } \\
\text { (I-J) }\end{array}$ & Sig. \\
\hline $\begin{array}{l}\text { Dependent } \\
\text { Autonomous Learning }\end{array}$ & $\begin{array}{l}\text { variable: } \\
\text { Efficacy of }\end{array}$ & Quizzes to & Support \\
\hline Scheffe & $20-24$ & $\begin{array}{l}35 \text { or more } \\
\text { than } 35\end{array}$ & $.493 *$ & .024 \\
\hline * The mean difference is significant at the .05 level. $\mathrm{n}=358$
\end{tabular}

\subsection{Students and Teachers' Roles}

The data analysis also indicated that the majority of the students agreed $(46.5 \%, n=167)$ or totally agreed $(24.5 \%$, $n=88)$ with the idea of being assessors of their own learning and decide what to assess and when to assess it, as well as with the opinion that stated that the teachers' role as guides or counselors in the process was essential, in that case 55,4\% (n=199) agreed, and 27.3\% ( $\mathrm{n}=98)$ totally agreed. The analysis of the data revealed that there were statistically significant differences (CI 95\%) between age groups ( $p=.000)$ in the dependent variable that referred to the idea of being assessors of their own learning and decide what to assess and when to assess it. The Scheffe posthoc test (Table 6) stated that there were statistically significant differences between the mean of the youngest $(20-24: \bar{x}=4.25 \& 25-29$ : $\bar{x}=4.34)$ and the oldest participants of the study $(30-34: \bar{x}=3.55 \& 35$ ore more than $35: \bar{x}=3.20)$.

Table 6. Multiple Comparisons

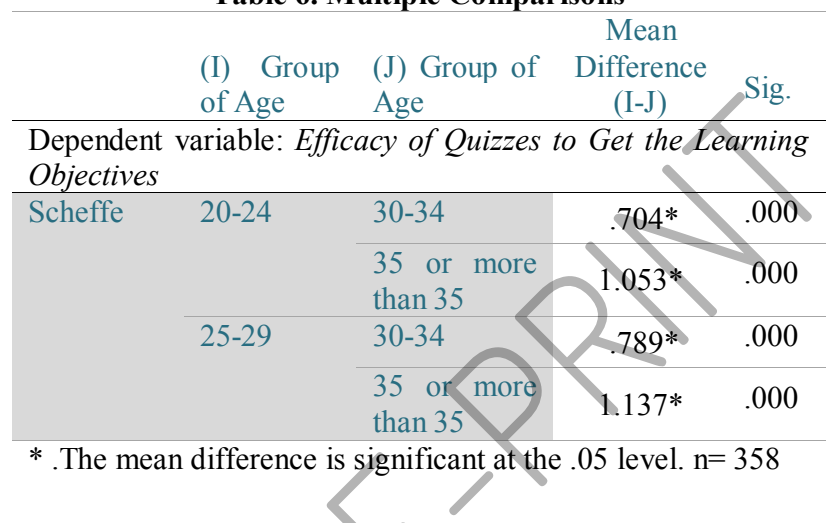

\section{CONCLUSIONS AND DISCUSSION}

The findings of this research have provided evidences about the positive students' perception of the effectiveness of online assessment and self-assessment quizzes towards the possibitities that they offered to practice and improve reading and listening comprehension as well as grammatical competence and vocabulary [13, 18].

In relation to the questions that explored the possibilities of the feedback provided, the study found that the participants appreciated in a positive way its immediacy [3,10,19]. In particular, the research identified its adequacy to guide participants' learning and to offer them a more realistic impression of their level of the second language in terms of reading, listening, grammar, and vocabulary.

The data of our study extended understanding of how online assessment and self-assessment quizzes could be used in second language teaching to get the learning objectives, to motivate students' learning, and to encourage the study of the subject [6]. Similar results were obtained in different researches about the effectiveness of technological tools as podcast, videocast, forums or wikis $[15,16]$.

Moreover, the availability of the quizzes allowed a practice that was essential in the learning process of a second language to help students to be in contact with the subject, and to feel more confident to take the assessments quizzes [11].

This study proved that autonomous learning was fostered through the implementation of the quizzes [5] since they granted the participants' active role in their progress what allowed them to determine language proficiency and to reflect about its acquisition, as well as, to carry out a self-monitoring of their learning towards specific necessities, taking responsibility for their learning, and deciding what they needed to learn and when they needed to do it [17].

Finally, we stated how the students felt themselves as assessors of their own learning, although nothing would have been possible without the essential roles of teachers as guides and counselors of the process.

\section{REFERENCES}

[1] Andrade, H., and Du, Y. 2007. Student responses to criteria-referenced self-Assessment. Assessment and Evaluation in Higher Education. 32, 2 (Jun. 2007), 159- 181. DOI=10.1080/02602930600801928

[2] Anikweze, C.M. 2005. Assessment and the future of schooling and learning. 31st Annual Conference of the International Association for Educational Assessment. (Abuja, Nigeria, September, 04-09, 2005). 
[3] Angus, S. D., and Watson, J. 2009. Does Regular Online Testing Enhance Student Learning in The Numerical Sciences? Robust Evidence from a Large Data Set. British Journal of Educational Technology. 40, 2, (Mar. 2009), 255-272. DOI=10.1111/j.14678535.2008.00916.x

[4] Arnal, Rincón \& Latorre. 1994. Investigación educativa. Fundamentos y metodología. Labor, Barcelona.

[5] Blanco, M., and Ginovart, M. 2009. Creating Moodle Quizzes for the Subjects of Mathematics and Statistics Corresponding to the First Years in Engineering Studies. 1st International Conference on Education and New Learning Technologies (Barcelona, Spain, July 06-08, 2009).

[6] Bock, M, and McColl, J. 2014. Using On-Line Quizzes to help Students Learn Probability and Statistics. In Proceedings of the Ninth International Conference on Teaching Statistics (Flagstaff, Arizona, USA, July 13-18, 2014).

[7] Cohen, L., Manion, L \& Morrison, K. 2007. Research Methods in Education. Routledge, London.

[8] Coleman, H., and Unrau, Y. A. 2005. In Social Work: Research and Evaluation. Quantitative and Qualitative Approaches, R. M. Grinnell and Y. A. Unrau, Eds. Oxford University Press, New York, 403-420.

[9] Creswell, J. 2005. Educational Research: Planning, Conducting, and Evaluating Quantitative and Qualitative Research. Pearson Education, Upper Saddle River.

[10] Dopper, S. M., and Sjoer, E. 2004. Implementing Formative Assessment in Engineering Education: The Use of the Online Assessment System Etude. European Journal of Engineering Education. 29, 2 (Jan. 2007), 259-266. DOI:10.1080/0304379032000157187

[11] Gholami, V., and Morady, M. The Effect of Weekly Quizzes on Students' Final Achievement Score. I. J. Modern Education and Computer Science. 5, 1, (Jan. 2013), 36-41.

[12] Hernández, R., Fernández, C. \& Baptista, P. 2010. Metodología de la investigación. McGraw Hill, México.

[13] Hirschel, R. 2012. Moodle: Students' Perspectives on Forums, Glossaries and Quizzes. The Jaltcalljournal. 8, 2, (Aug. 2012), 95112.

[14] Moges, B. 2013. Continuous Assessment Issues and Practices in Secondary Schools of Oromia Regional State, Ethiopia: The "Big Picture" of Assessment Mechanism. Palgo Journal of Education Research. 1, 1, (Nov. 2013), 19-41.

[15] Pinto-Llorente, A. M., Sánchez-Gómez, M. C., and García-Peñalvo, F. J. 2015. To Be or Not to Be Successful? That Does Not Only Depend on Technology, But Also on Human Factors. Journal of Cases on Information Technology, 17, 1 (Jan. 2015), 51-69. DOI= http://dx.doi.org/10.4018/JCIT.2015010104

[16] Pinto-Llorente, A. M., Sánchez-Gómez, M. C. and García-Peñalvo, F. J. 2016. Assessing the Effectiveness of Interactive and Collaborative Resources to Improve Reading and Writing in English. International Journal of Human Capital and Information Technology Professionals (IJHCITP), 7, 1 (Jan. 2016) 66-85. DOI=10.4018/IJHCITP.2016010105

[17] Pinto-Llorente, A. M., et al. 2016. Students' Perceptions and Attitudes Towards Asynchronous Technological Tools in BlendedLearning Training to Improve Grammatical Competence in English as a Second Language. Computers in Human Behavior. In Press. DOI= http://dx.doi.org/10.1016/j.chb.2016.05.071

[18] Salas-Moreira, L., Arauzo-Azifra, A., and García-Hernández, L. 2012. Analysis of Online Quizzes as a Teaching and Assessment Tool. Journal of Technology and Science Education. 2, 1, (Feb. 2012), 39-45. DOI=http://dx.doi.org/10.3926/jotse.30

[19] Smith, G. 2007. How does student performance on formative assessments relate to learning assessed by exams? Journal of College Science Teaching. 36, 7, (Jul. 2007), 28-34.

[20] Steegmann, C., Huertas, M. A., Juan, A. A., and Prat, M. 2008. E-learning de las asignaturas del ámbito matemático-estadístico en las universidades españolas: oportunidades, retos, estado actual y tendencias. Revista de Universidad y Sociedad del Conocimiento. 5, 2, (Oct. 2008), 1-14. 